\title{
A comparative study of treatment outcome in younger and older patients with locally advanced oral cavity and oropharyngeal cancers treated by chemoradiation
}

\author{
Rituparna Biswas, Anirban Halder, Anshuman Ghosh, Sajal Kumar Ghosh
}

\begin{abstract}
Background: Evidence suggests that older patients with oral cavity and oropharyngeal cancers may behave differently from their younger peers. Aim: The aim of this study is to determine if there is difference in responses, survival, and toxicities between young patients ( $\leq 40$ years of age) with oral cavity and oropharyngeal cancers and older patients (>40 years of age) treated with concurrent chemoradiation. Materials and Methods: Sixty-one patients with unresectable, locally advanced oral cavity and oropharyngeal cancers received concomitant chemoradiation to a dose of $70 \mathrm{Gray}$ in 35 fractions over 7 weeks with concomitant weekly cisplatin $\left(40 \mathrm{mg} / \mathrm{m}^{2}\right)$. These patients were then distributed in two arms.Arm-A patients having age $\leq 40$ years and Arm-B patients having age $>40$ years, and the two arms were assessed for treatment outcome. Results: The overall response rate (complete responders + partial responders) evaluated using response evaluation criteria in solid tumors criteria version I.I was equivalent in both groups ( $80.76 \%$ in $A r m-A$ and $74.28 \%$ in $A r m-B ; P=0.93)$. Older patients (>40 years) experienced more acute mucositis and xerostomia $(P<0.5)$; although not statistically significant, more acute skin and pharynx toxicities were also observed in this group. Higher late salivary gland toxicity $(P<0.5)$ was also seen in older patients; however, disease-free survival and progression-free survival were found to be similar in both groups. Conclusions: Older patients with locally advanced oral cavity and oropharyngeal cancers have similar response rates and survival as compared to their younger counterparts but may experience higher treatment-related toxicities.

Key words: Concurrent chemoradiation, disease-free survival, mucositis, oropharyngeal cancer, xerostomia
\end{abstract}

\section{Introduction}

Oral cancer is a major problem in the Indian subcontinent where it ranks among the top three types of cancer in the country. ${ }^{[1]}$ Indiscriminate use of tobacco in its various forms, alcohol drinking, betel nut chewing, poor dental care, poor diet, and human papillomavirus (HPV) is the most common risk factors for oral cancer. ${ }^{[2,3]}$ There has also been a recent rise in cases of oropharyngeal cancer linked to infection with HPV. Nearly $60 \%$ of newly diagnosed patients present with locally advanced, but nonmetastatic disease. ${ }^{[4]}$ In case of resectable disease, radical surgery is combined with postoperative radiation or chemoradiation though this is often associated with cosmetic and functional impairment affecting the quality of life. Concurrent chemoradiation therapy is the current standard of care for patients with locally advanced, unresectable squamous cell carcinoma of the oral cavity and oropharyngeal cancers. ${ }^{[4]}$ Verschuur et al. differentiated between young and old patients with head-and-neck cancers as young ( $\leq 40$ years) and old ( $>40$ years).$^{[5]}$

The effort of this study is to determine if there is difference in responses, survival, and toxicities between young patients ( $\leq 40$ years of age) with locally advanced oral cavity and oropharyngeal cancers and older patients ( $>40$ years of age) treated with concurrent chemoradiation.

\section{Materials and Methods}

\section{Participants}

In this prospective, observational, open-labeled, and comparative study done at Radiotherapy outpatient department of a tertiary care teaching hospital from January 2013 to August 2014, patients, with histologically proven locally advanced squamous cell carcinoma of oral cavity and oropharynx who were deemed unresectable, were eligible in this study. The

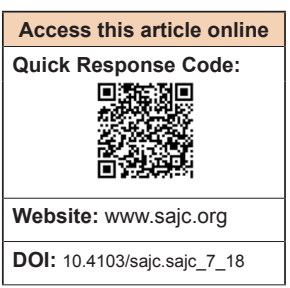

Department of Radiation Oncology, Institute of Post-Graduate Medical Education and Research, Kolkata, West Bengal, India Correspondence to: Dr.Anirban Halder, E-mail: dranirban666@gmail.com inclusion criteria were patients with the age of 18-70 years, Eastern Cooperative Oncology Group performance status $\leq 2$, adequate bone marrow, liver, and renal function measured with blood tests, no previous history of treatment of cancer or any other coexisting primary malignancy, no evidence of distant metastases by clinical, radiological, or cytohistopathological examination and without any severe systemic comorbidity. The study protocol was approved by the Institutional Ethics Committee, and written informed consent was obtained from all the study participants.

\section{Study technique}

Participants fulfilling the above criteria received concomitant chemoradiation. Radiotherapy was administered as external beam radiotherapy to a dose of 70 Gray (Gy) in 35 fractions over 7 weeks by a megavoltage beam utilizing tele-Cobalt- 60 . Concurrent cisplatin of dose $40 \mathrm{mg} / \mathrm{m}^{2}$ was given weekly with adequate prehydration. Then, with patients receiving the treatment were distributed in two arms: Arm-A patients having age $\leq 40$ years and Arm-B patients having age $>40$ years, and the two arms were assessed for treatment outcome. The sample size of this study was 61 (Arm-A -26; Arm-B -35). Pretreatment and posttreatment data were collected in case record forms which included history taking, detailed clinical examination, radiological assessment (contrast-enhanced computed tomography [CECT] scan of head and neck and chest X-ray posteroanterior view), cytology (histopathology or fine-needle aspiration), and laboratory investigations (complete blood count, liver function test, and renal function test).

The primary study endpoint was tumor response, assessed by response evaluation criteria in solid tumors (RECIST) guideline (version 1.1) regarding complete response (CR), partial response (PR), progressive disease, and stable

This is an open access journal, and articles are distributed under the terms of the Creative Commons Attribution-NonCommercial-ShareAlike 4.0 License, which allows others to remix, tweak, and build upon the work non-commercially, as long as appropriate credit is given and the new creations are licensed under the identical terms.

For reprints contact: reprints@ medknow.com

How to cite this article: Biswas R, Halder A, Ghosh A, Ghosh SK. A comparative study of treatment outcome in younger and older patients with locally advanced oral cavity and oropharyngeal cancers treated by chemoradiation. South Asian J Cancer 2019;8:47-51. 
disease (SD). Secondary endpoints were acute and delayed organ toxicities and disease-free survival and progression-free survival (DFS and PFS). During radiotherapy, weekly toxicity assessment was done by clinical status, laboratory investigations, and radiological test (if required) and graded according to (radiation therapy oncology group (RTOG)/European organization for research and treatment of cancer) acute and chronic radiation morbidity criteria and Common Terminology Criteria for Adverse Events version 4.0 (CTCAEv4). To assess DFS and PFS, the patients were followed up thereafter at 2-monthly intervals until the end of the study with clinical examination and CECT scan of the head and neck done 6 monthly or before in patients with suspicion for recurrence. Locoregional recurrence was proven by biopsy.

Treatment technique

Patients were positioned in supine position with the neck extended and immobilized with the help of headrest and thermoplastic immobilization mask. Conventional two-dimensional treatment planning was done with the help of anatomical bony landmarks. A bite block was used in case of oral tongue and floor of the mouth cancer to depress the tongue away from the palate. Wherever, applicable primary disease site and its draining echelon group of lymph nodes were encompassed with parallel-opposed radiation portals with separate fields for low neck nodal irradiation.

The dose was prescribed at the center of interfield distance in lateral, parallel-opposed field and at depth of $3 \mathrm{~cm}$ in case of direct anterior field used for lower neck treatment. "Off cord" field was practiced for all patients after 45 Gy. If any residual neck disease were left beyond the 45 Gy dose cutoff, tangential radiation portals were used for boosting. For lesions involving the skin or tracheostomy tube stoma, boluses were used to increase the superficial skin dose. Any type of treatment interruptions resulting from treatment toxicities was calculated using the biological equivalent dose (BED).

\section{Statistical analysis}

Statistical analysis was done using SPSS version 16 . The $t$-test/Chi-square/Fisher-exact test was used for comparing baseline profiles, the response rates, and toxicities among patients of two treatment arms, with $P<0.05$ as statistically significant. DFS was measured from the date of declaration of CR to the date of first relapse (locoregional or distant metastasis) or death. PFS was measured from the date of declaration of PR or SD to the date of first progression or death. The DFS and PFS were determined using the Kaplan-Meier survival analysis with log-rank test for comparing the DFS and PFS.

\section{Results}

A total of 63 patients were assessed for eligibility for the study. Out of these, 61 patients were allocated to treatment after exclusion. Then, the patients were distributed into two arms - Arm-A $(n=26)$ with patients' age of $\leq 40$ years and Arm-B $(n=37)$ with patients' age of $>40$ years [Figure 1]. Baseline profiles of both groups were comparable regarding sex distribution, pretreatment hemoglobin level, performance status, stage, and primary site. Comparison of demographic profiles among different treatment arms showed no statistically significant difference $(P>0.05$ signifies statistically nonsignificant) [Table 1].

\section{Response evaluation}

A total of 61 patients were evaluated for response at stipulated 6-8 weeks posttreatment using RECIST criteria version 1.1. The overall response rate $(\mathrm{CR}+\mathrm{PR})$ was equivalent in both groups (80.76\% in Arm-A and $74.28 \%$ in Arm-B) with statistical analysis showing no significant difference in response rates between the two arms $(P=0.93)$ [Table 2].

On subgroup analysis, there was no statistically significant difference in overall response rate $(\mathrm{CR}+\mathrm{PR})$ between two arms in the oral cavity and oropharyngeal cancers with $P$ values of 0.99 and 0.42 , respectively [Table 3 ].

\section{Comparison of toxicity profile}

Combined acute Grade 2 and Grade 3 mucositis was 38.46\% and $71.42 \%$ in Arm-A and Arm-B, respectively $(P=0.041)$ whereas Grade 2 acute salivary gland toxicity was $34.61 \%$ and $60 \%$, respectively, $(P=0.025)$ which shows there were statistically significant higher mucositis and acute salivary gland toxicity in Arm-B, i.e., in patients with age of $>40$ years. Furthermore, there was more acute pharynx toxicity noted in patients of age $>40$ years, combined Grade 2 and Grade 3 toxicity being $42.31 \%$ and $68.57 \%$, respectively, in Arm- A and Arm-B, respectively $(P=0.025)$. The skin toxicity assessed by RTOG acute morbidity scoring shows a higher percentage of older patients getting Grade 2 and Grade 3 toxicity; however, it has not been found to be statistically significant [Table 4].

Among the late toxicities assessed by RTOG late morbidity scoring, statistically significant higher toxicity in older age group has only been noted for xerostomia where combined Grades 2 and 3 toxicity is $45.46 \%$ and $82.75 \%$, respectively, in Arm-A and Arm-B with $P=0.018$ [Table 5].

There was a statistically insignificant difference between younger and older age group patients regarding vomiting and diarrhea using CTCAEv4.

\section{Survival analysis}

With a mean follow-up of 11.1 months, DFS seen for those who underwent CR was similar to both groups of patients [Figure 2]. PFS has been derived for patients who underwent PR or SD at the end of the treatment. With a mean follow-up of 9.2 months, PFS was observed to be similar to both groups [Figure 3].

\section{Discussion}

Existing literature suggests that older patients with oral cavity and oropharyngeal cancers may behave differently from their younger peers. One theory that partially explains the increasing incidence of cancer in the elderly is the prolonged exposure to the environmental factors such as tobacco or alcohol in the setting of immunosenescence. ${ }^{[6]}$ This differential in exposures and

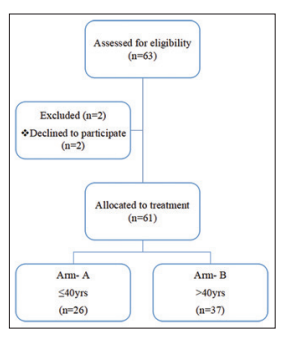

Figure 1: Flowchart for study design

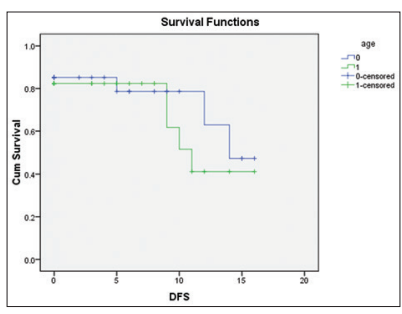

Figure 2: Comparison of diseasefree survival using the Kaplan-Meier curve
South Asian Journal of Cancer $\bullet$ Volume 8 Issue 1 January-March 2019 
Table 1: Baseline profile comparison

\begin{tabular}{|c|c|c|c|}
\hline & \multicolumn{2}{|c|}{ Arms } & \multirow[t]{2}{*}{$P$} \\
\hline & $\begin{array}{c}\text { Arm-A } \\
\text { Age } \leq 40 \text { years }(n=26), n(\%)\end{array}$ & $\begin{array}{c}\text { Arm-B } \\
\text { Age }>40 \text { years }(n=35), n(\%)\end{array}$ & \\
\hline \multicolumn{4}{|c|}{ 然 } \\
\hline Male & $23(88.46)$ & $30(85.71)$ & \multirow[t]{2}{*}{0.38} \\
\hline Female & $3(11.53)$ & $5(14.28)$ & \\
\hline \multicolumn{4}{|l|}{ Hemoglobin (gm \%) } \\
\hline$\leq 10$ & $7(26.92)$ & $10(28.57)$ & \multirow[t]{3}{*}{0.44} \\
\hline$>10$ & $19(73.07)$ & $25(71.42)$ & \\
\hline Mean \pm SE & $10.5 \pm 0.414$ & $10.19 \pm 0.357$ & \\
\hline \multicolumn{4}{|l|}{ ECOG } \\
\hline ECOG 1 & $18(69.2)$ & $25(71.42)$ & \multirow[t]{2}{*}{0.42} \\
\hline ECOG 2 & $8(30.76)$ & $10(28.57)$ & \\
\hline \multicolumn{4}{|l|}{ Primary site } \\
\hline Oral cavity & $20(76.92)$ & $26(74.28)$ & \multirow[t]{2}{*}{0.40} \\
\hline Oropharynx & $6(23.07)$ & $9(25.71)$ & \\
\hline \multicolumn{4}{|l|}{ AJCC stage } \\
\hline III & $10(38.46)$ & $11(31.42)$ & \multirow[t]{3}{*}{0.84} \\
\hline IVA & $9(34.61)$ & $14(40)$ & \\
\hline IVB & $7(26.92)$ & $10(28.57)$ & \\
\hline \multicolumn{4}{|c|}{ Primary site of oral cavity and oropharynx with stage } \\
\hline \multicolumn{4}{|l|}{ Oral cavity } \\
\hline AJCC Stage III & $7(35)$ & $8(30.76)$ & \multirow[t]{3}{*}{0.88} \\
\hline AJCC Stage IVA & $7(35)$ & $11(42.30)$ & \\
\hline AJCC Stage IVB & $6(30)$ & $7(26.92)$ & \\
\hline \multicolumn{4}{|l|}{ Oropharynx } \\
\hline AJCC Stage III & $3(50)$ & $3(33.33)$ & \multirow[t]{3}{*}{0.73} \\
\hline AJCC Stage IVA & $2(33.33)$ & $3(33.33)$ & \\
\hline AJCC Stage IVB & $1(16.66)$ & $3(33.33)$ & \\
\hline \\
\hline \multicolumn{4}{|c|}{ Number of patients $(n=61), n(\%)$} \\
\hline $21-30$ & & $2(3.28)$ & \\
\hline $31-40$ & & $24(39.34)$ & \\
\hline $41-50$ & & $6(9.83)$ & \\
\hline $51-60$ & & $19(31.15)$ & \\
\hline $61-70$ & & $10(14.28)$ & \\
\hline
\end{tabular}

ECOG=Eastern Cooperative Oncology Group, SE=Standard error

Table 2: Response assessment

\begin{tabular}{lccc}
\hline \multirow{2}{*}{ Response } & \multicolumn{2}{c}{ Arms } & $P$ \\
\cline { 2 - 3 } & $\begin{array}{c}\text { Age } \leq \mathbf{4 0} \text { years } \\
(n=\mathbf{2 6}), n(\%)\end{array}$ & $\begin{array}{c}\text { Age }>\mathbf{4 0} \text { years } \\
(n=35), n(\%)\end{array}$ & \\
\hline $\mathrm{CR}$ & $15(57.69)$ & $18(51.43)$ & 0.93 \\
$\mathrm{PR}$ & $6(23.07)$ & $8(22.85)$ & \\
$\mathrm{SD}$ & $3(11.54)$ & $5(14.28)$ & \\
$\mathrm{PD}$ & $2(7.69)$ & $4(11.43)$ & \\
\hline $\mathrm{CR}=$ Complete response, $\mathrm{PR}=$ Partial response, $\mathrm{SD}=$ Stable disease, $\mathrm{PD}=$ Progressive
\end{tabular}

disease

immunosenescence may lead to biological differences in the solid tumors that develop in older patients compared with their younger peers. ${ }^{[7]}$ These biological differences could lead to differences in the way tumors respond to antineoplastic therapy. There are studies which have claimed that these cancers in younger patients are more aggressive than in older patients and on the basis of which more aggressive therapy should be advocated. ${ }^{[8-11]}$ On the contrary, there had been several other studies by von Doersten et al., ${ }^{[12]}$ Funk et al., ${ }^{[13]}$ and Gilroy et al. ${ }^{[14]}$ who have found a significant difference in the overall survival in favor of younger patients. However, there is evidence in contrast to the above studies which have not reported any significant difference between the two groups. ${ }^{[15-17]}$ Hence, the question as to whether age has a significant impact or not on treatment outcomes still remains unanswered. Verschuur et al. performed a matched control study describing the outcome of 185 previously untreated head-and-neck cancer patients $<40$ years of age treated at the Princess Margaret Hospital, Toronto, Ontario, Canada, between 1958 and 1992. ${ }^{[5]}$ The young patient group was compared with a control group older patients ( $>40$ years of age) which were selected randomly from an entire cohort of patients $(n=10,072)$ and matched for site, sex, and date of presentation. The 5-year, cause-specific survival in both groups was not statistically different $(72 \%$ vs. $68 \%, P=0.91)$. It concluded that young patients do not have a worse prognosis than a matched older patient group in this case-controlled study. Similar results were reflected in our study too where no significant difference in DFS and PFS has been observed in young and older groups of patients. However, evidence suggests that older patients may experience worse toxicity ${ }^{[18,19]}$ especially with treatment intensification as has also been reported in our study. There had been more acute mucositis, xerostomia, and late salivary gland toxicity observed in older cohort of our study. Despite higher toxicities in older age group, the patients could cope remarkably with adequate supportive interventions without much treatment breaks. 
Table 3: Response assessment according to primary site

\begin{tabular}{|c|c|c|c|c|}
\hline \multicolumn{5}{|c|}{ Comparison of response according to primary site } \\
\hline \multirow[t]{2}{*}{ Primary site } & \multirow[t]{2}{*}{ Response } & \multicolumn{2}{|c|}{ Arms } & \multirow[t]{2}{*}{$P$} \\
\hline & & Age $<40$ years $(n=26), n(\%)$ & Age $>40$ years $(n=35), n(\%)$ & \\
\hline \multirow[t]{4}{*}{ Oral cavity } & $\mathrm{CR}$ & $10(38.46)$ & $15(42.85)$ & 0.99 \\
\hline & PR & $5(25)$ & $6(23.07)$ & \\
\hline & SD & $3(15)$ & $4(15.38)$ & \\
\hline & $\mathrm{PD}$ & $2(10)$ & $3(11.53)$ & \\
\hline \multirow[t]{4}{*}{ Oropharynx } & $\mathrm{CR}$ & $5(83.33)$ & $3(33.33)$ & 0.42 \\
\hline & PR & $1(16.66)$ & $2(22.22)$ & \\
\hline & SD & 0 & $1(11.11)$ & \\
\hline & $\mathrm{PD}$ & 0 & $1(11.11)$ & \\
\hline
\end{tabular}

$\mathrm{CR}=$ Complete response, $\mathrm{PR}=$ Partial response, $\mathrm{SD}=$ Stable disease, $\mathrm{PD}=$ Progressive disease

Table 4: RTOG acute toxicities

\begin{tabular}{|c|c|c|c|}
\hline & \multicolumn{2}{|c|}{ Arms } & \multirow[t]{2}{*}{$P$} \\
\hline & Age $<40$ years $(n=26), n(\%)$ & Age $>40$ years $(n=35), n(\%)$ & \\
\hline \multicolumn{4}{|c|}{ Mucous membrane } \\
\hline Group 1 & $16(61.53)$ & $10(28.57)$ & \multirow[t]{3}{*}{0.041} \\
\hline Group 2 & $8(30.77)$ & $19(54.28)$ & \\
\hline Group 3 & $2(7.69)$ & $6(17.14)$ & \\
\hline \multicolumn{4}{|c|}{ Salivary gland } \\
\hline Group 1 & $17(65.38)$ & $14(40)$ & \multirow[t]{2}{*}{0.025} \\
\hline Group 2 & $9(34.61)$ & $21(60)$ & \\
\hline \multicolumn{4}{|l|}{ Pharynx } \\
\hline Group 1 & $15(57.69)$ & $11(31.43)$ & \multirow[t]{3}{*}{0.025} \\
\hline Group 2 & $10(38.47)$ & $20(57.15)$ & \\
\hline Group 3 & $1(3.84)$ & $4(11.42)$ & \\
\hline \multicolumn{4}{|l|}{ Skin } \\
\hline Group 1 & $21(80.76)$ & $23(65.71)$ & \multirow[t]{3}{*}{0.22} \\
\hline Group 2 & $5(19.23)$ & $9(25.71)$ & \\
\hline Group 3 & 0 & $3(8.57)$ & \\
\hline \multicolumn{4}{|c|}{ Acute larynx } \\
\hline Group 0 & $17(65.38)$ & $18(51.42)$ & \multirow[t]{3}{*}{0.30} \\
\hline Group 1 & $6(23.07)$ & $10(28.57)$ & \\
\hline Group 2 & $3(11.53)$ & $7(20)$ & \\
\hline
\end{tabular}

RTOG=Radiation therapy oncology group

Table 5: RTOG late toxicities

\begin{tabular}{|c|c|c|c|}
\hline & \multicolumn{2}{|c|}{ Group } & \multirow[t]{2}{*}{$P$} \\
\hline & Age $<40$ years $(n: 26-4=22), n(\%)$ & Age $>40$ years $(n: 35-6=29), n(\%)$ & \\
\hline \multicolumn{4}{|l|}{ Skin } \\
\hline Group 0 & $17(77.27)$ & $19(65.52)$ & 0.36 \\
\hline Group 1 & $5(22.73)$ & $10(34.48)$ & \\
\hline \multicolumn{4}{|c|}{ Subcutaneous tissue } \\
\hline Group 0 & $17(77.27)$ & $19(65.52)$ & 0.39 \\
\hline Group 1 & $5(22.73)$ & $8(27.59)$ & \\
\hline Group 2 & $0(0.00)$ & $2(9.09)$ & \\
\hline \multicolumn{4}{|c|}{ Mucous membrane } \\
\hline Group 0 & $17(77.27)$ & $21(72.41)$ & 0.69 \\
\hline Group 1 & $5(22.73)$ & $8(27.59)$ & \\
\hline \multicolumn{4}{|c|}{ Late salivary gland } \\
\hline Group 1 & $12(54.54)$ & $5(17.24)$ & 0.018 \\
\hline Group 2 & $8(36.36)$ & $20(68.96)$ & \\
\hline Group 3 & $2(9.1)$ & $4(13.79)$ & \\
\hline
\end{tabular}

RTOG=Radiation therapy oncology group

Hence, with the caveats of relatively small sample size and limited follow-up, our study has shown that younger patients with oral cavity and oropharyngeal cancers have similar survival and treatment response as their older counterparts, although treatment-related toxicities such as acute and late salivary gland toxicity, acute mucositis, and acute pharynx toxicity were higher in case of older patients.

\section{Conclusions}

With current treatment modalities, older patients with locally advanced oral cavity and oropharyngeal cancers have similar response rates and survival as compared to their younger counterparts but may experience higher treatment-related toxicities compared with their younger peers. Further studies South Asian Journal of Cancer • Volume 8 • Issue 1 • January-March 2019 
Biswas, et al.: Treatment outcome in younger and older patients with locally advanced oral cavity and oropharyngeal cancers

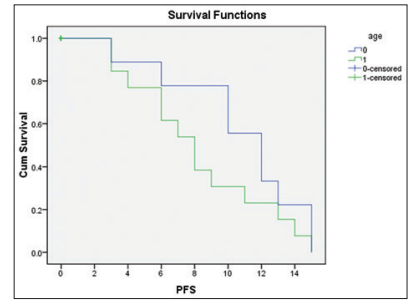

Figure 3: Comparison of progression-free survival using the Kaplan-Meier curve

with larger sample size and longer follow-up period are required for establishing this observation.

\section{Financial support and sponsorship}

Nil.

\section{Conflicts of interest}

There are no conflicts of interest

\section{References}

1. Elango JK, Gangadharan P, Sumithra S, Kuriakose MA. Trends of head and neck cancers in urban and rural India. Asian Pac J Cancer Prev 2006;7:108-12.

2. Chaturvedi AK, Anderson WF, Lortet-Tieulent J, Curado MP, Ferlay J, Franceschi S, et al. Worldwide trends in incidence rates for oral cavity and oropharyngeal cancers. J Clin Oncol 2013;31:4550-9.

3. Lin WJ, Jiang RS, Wu SH, Chen FJ, Liu SA. Smoking, alcohol, and betel quid and oral cancer: A prospective cohort study. J Oncol 2011;2011:525976.

4. Brizel DM, Adelstein DJ. Locally advanced squamous carcinoma of the head and neck. In: Halperin EC, Wazer DE, Perez CA, Brady LW, editors. Perez and Brady's Principles and Practices of Radiation Oncology. $6^{\text {th }}$ ed. Philadelphia: Lippincott Williams \& Wilkins; 2013. p. 719.

5. Verschuur HP, Irish JC, O'Sullivan B, Goh C, Gullane PJ, Pintilie M, et al. A matched control study of treatment outcome in young patients with squamous cell carcinoma of the head and neck. Laryngoscope 1999; 109:249-58.
6. VanderWalde NA, Fleming M, Weiss J, Chera BS. Treatment of older patients with head and neck cancer: A review. Oncologist 2013; 18:568-78.

7. Piantanelli L. Cancer and aging: From the kinetics of biological parameters to the kinetics of cancer incidence and mortality. Ann N Y Acad Sci 1988;521:99-109.

8. Lund VJ, Howard DJ. Head and neck cancer in the young: A prognostic conundrum? J Laryngol Otol 1990;104:544-8.

9. Amsterdam JT, Strawitz JG. Squamous cell carcinoma of the oral cavity in young adults. J Surg Oncol 1982;19:65-8.

10. Son YH, Kapp DS. Oral cavity and oropharyngeal cancer in a younger population. Review of literature and experience at Yale. Cancer 1985;55:441-4.

11. Sasaki T, Moles DR, Imai Y, Speight PM. Clinico-pathological features of squamous cell carcinoma of the oral cavity in patients $<40$ years of age. J Oral Pathol Med 2005;34:129-33.

12. von Doersten PG, Cruz RM, Rasgon BM, Quesenberry CP Jr., Hilsinger RL Jr. Relation between age and head and neck cancer recurrence after surgery: A multivariate analysis. Otolaryngol Head Neck Surg 1995;113:197-203.

13. Funk GF, Karnell LH, Robinson RA, Zhen WK, Trask DK, Hoffman HT, et al. Presentation, treatment, and outcome of oral cavity cancer: A national cancer data base report. Head Neck 2002;24:165-80.

14. Gilroy JS, Morris CG, Amdur RJ, Mendenhall WM. Impact of young age on prognosis for head and neck cancer: A matched-pair analysis. Head Neck 2005;27:269-73.

15. Burzynski NJ, Flynn MB, Faller NM, Ragsdale TL. Squamous cell carcinoma of the upper aerodigestive tract in patients 40 years of age and younger. Oral Surg Oral Med Oral Pathol 1992;74:404-8.

16. Clarke RW, Stell PM. Squamous carcinoma of the head and neck in the young adult. Clin Otolaryngol 1992;17:18-23.

17. McGregor AD, Rennie JS. Intra-oral squamous cell carcinoma in patients under 40 years of age. A report of 13 cases and review of the literature. Br J Plast Surg 1987;40:270-3.

18. Pignon T, Horiot JC, Van den Bogaert W, Van Glabbeke M, Scalliet P. No age limit for radical radiotherapy in head and neck tumours. Eur J Cancer 1996;32A: 2075-81.

19. Allal AS, Maire D, Becker M, Dulguerov P. Feasibility and early results of accelerated radiotherapy for head and neck carcinoma in the elderly. Cancer 2000;88:648-52. 